13,11

\title{
Структурные фазовые превращения при твердофазной реакции В двухслойной тонкопленочной наносистеме Al/Fe
}

\author{
(C) P.P. Алтунин ${ }^{1}$, E.T. Моисеенко ${ }^{1}$, С.М. Жарков ${ }^{1,2}$ \\ ${ }^{1}$ Сибирский феедеральный университет, \\ Красноярск, Россия \\ ${ }^{2}$ Институт физики им. Л.В. Киренского ФИЦ КНЦ СО РАН, \\ Красноярск, Россия \\ E-mail: raltunin@gmail.com
}

Поступила в Редакцию 26 июня 2019 г.

В окончательной редакции 20 августа 2019 г.

Принята к публикации 20 августа 2019 г.

Методом in situ дифракции электронов исследованы процессы формирования фаз при твердофазной реакции между нанослоями $\mathrm{Fe}$ и $\mathrm{Al}$. Установлено, что процесс твердофазной реакции на границе нанослоев железа и алюминия начинается при $\approx 100^{\circ} \mathrm{C}$ с формирования неупорядоченного твердого раствора $\mathrm{Al}$ в $\alpha$-Fe. Показано, что в ходе дальнейшего нагрева последовательно формируются интерметаллические фазы $\mathrm{FeAl}_{6}$ и/или $\mathrm{Fe}_{2} \mathrm{Al}_{5}, \mathrm{FeAl}, \mathrm{Fe}_{3} \mathrm{Al}$.

Ключевые слова: тонкие пленки, $\mathrm{Al} / \mathrm{Fe}$, твердофазная реакция, фазообразование, дифракция электронов.

DOI: $10.21883 /$ FTT.2020.01.48754.543

\section{1. Введение}

Соединения с алюминием представляют интерес в различных сферах применения благодаря удачному сочетанию физико-химических свойств, например, хорошей устойчивости к окислению при высоких температурах и износостойкости, а также низкой стоимости производства, [1,2]. Тонкопленочные системы на основе $\mathrm{Al}$ и $\mathrm{Fe}$ являются перспективными в качестве теплостойких и коррозионностойких покрытий [3], металлизирующих слоев в микроэлектронике [4], материалов для высокоплотной магнитной записи информации $[5,6]$, а также реакционных нанопленок различного назначения [7-12].

Исследование процессов твердофазных реакций тонкопленочных систем представляют интерес не только с практической точки зрения, но и с фундаментальной. Процессы твердофазных реакций, протекающие в тонких пленках и массивных образцах, значительно отличаются. Твердофазные реакции в тонкопленочных системах могут протекать при более низких температурах по сравнению с массивным состоянием [13]. Одной из наиболее современных теоретических моделей, предсказывающих не только формирование первой фазы, но и последовательность образования фаз в процессе твердофазной реакции является модель эффективной теплоты формирования (Effective Heat of Formation, EHF [14]). Однако использование данной модели для тонкопленочной системы $\mathrm{Al} / \mathrm{Fe}$ затруднено из-за того, что расчет значений эффективной теплоты формирования фаз: $\mathrm{Fe}_{2} \mathrm{Al}_{5}, \mathrm{FeAl}_{6}, \mathrm{Fe}_{4} \mathrm{Al}_{13}, \mathrm{FeAl}_{2}$ и $\mathrm{FeAl}_{3}$ дает практически одинаковые величины, что не позволяет предсказать фазовую последовательность в данной системе. Применение модифицированной модели теплоты формирования (MEHF) для данной системы также не решает проблему с предсказанием фазовой последовательности [15].

Необходимо отметить, что в случае системы $\mathrm{Al} / \mathrm{Fe}$ экспериментальные исследования фазовой последовательности не дают однозначных результатов. В работах $[16,17]$ сообщалось, что первой в процессе твердофазной реакции формируется метастабильная фаза $\mathrm{FeAl}_{6}$, что противоречит результатам работ $[18,19]$, в которых первой регистрировали стабильную фазу $\mathrm{Fe}_{2} \mathrm{Al}_{5}$. В различных экспериментальных работах сообщалось о различных температурах начала реакции между слоями железа и алюминия, так в работах $[17,20]$ отмечено начало твердофазной реакции при температуре $250^{\circ} \mathrm{C}$, в работах $[16,18]$ при $300^{\circ} \mathrm{C}$, в работе [19] - при $350^{\circ} \mathrm{C}$.

Целью настоящей работы является определение температуры начала твердофазной реакции, а также установление последовательности образования интерметаллических фаз, формирующихся в процессе твердофазной реакции в тонкопленочной системе Al/Fe. Исследование проведено методом in situ дифракции электронов, что позволило детально исследовать как начальный этап твердофазной реакции, так и высокотемпературный диапазон.

\section{2. Методы получения и исследования образцов}

Двухслойные тонкопленочные наносистемы $\mathrm{Al} / \mathrm{Fe}$, исследованные в настоящей работе, получены на высоковакуумной установке MED-020 (Bal-Tec) методом электронно-лучевого испарения (базовый вакуум 

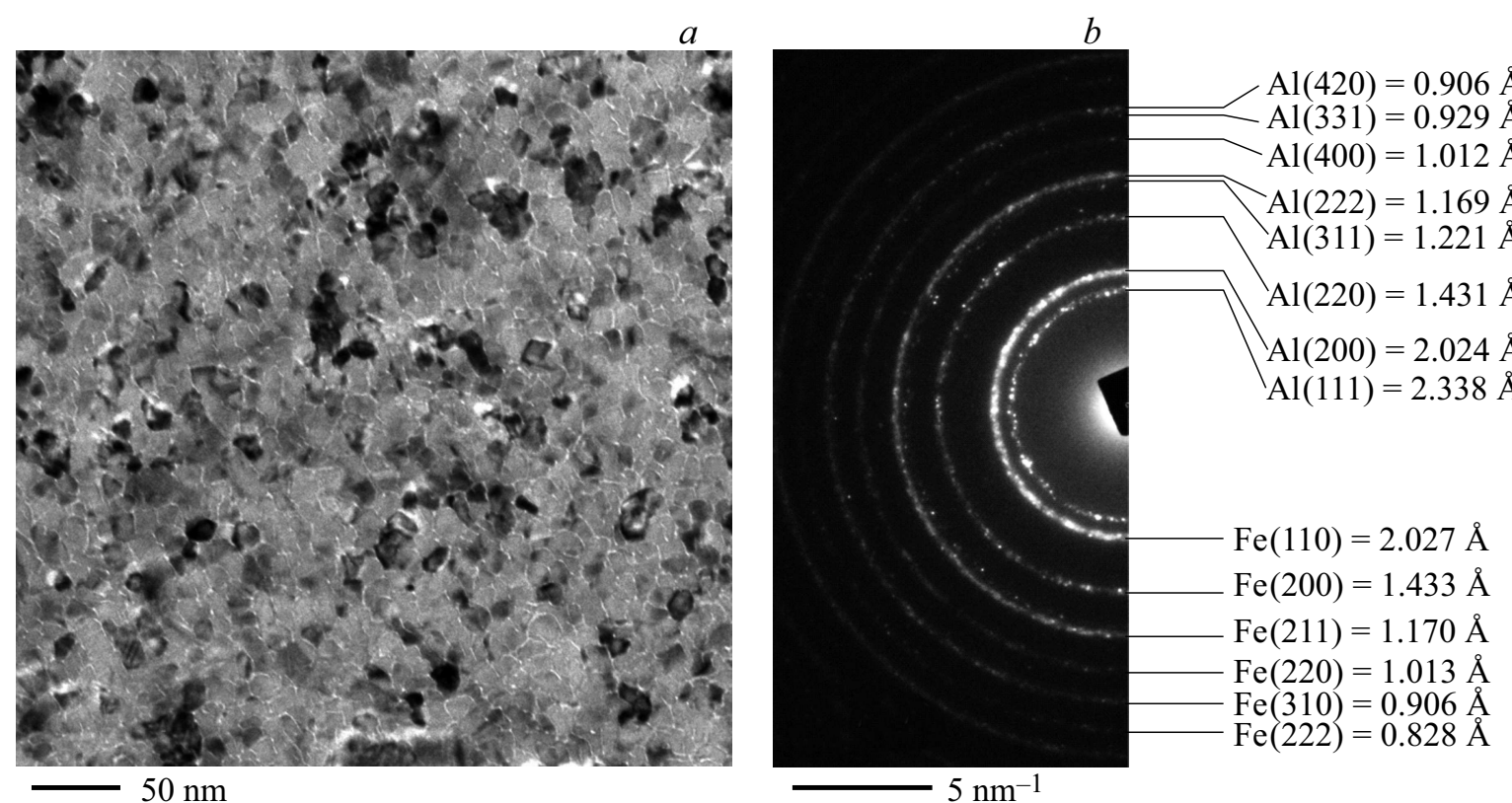

Рис. 1. Электронно-микроскопическое изображение $(a)$ и картина дифракции электронов $(b)$, полученные от тонкопленочной наносистемы Al/Fe в исходном состоянии.

$\left.5 \cdot 10^{-5} \mathrm{~Pa}\right)$. Температура подложек во время напыления равнялась комнатной. Для напыления использовали материалы высокой степени чистоты: $\mathrm{Fe}$ - 99.9\%, Al - 99.999\% [21]. Контроль толщины пленок во время напыления осуществляли при помощи кварцевого резонатора QSG-100 (точность определения интегральной толщины пленок - $0.01 \mathrm{~nm}$ ). Напыление слоев железа и алюминия осуществляли последовательно на подложку свежесколотого монокристалла $\mathrm{NaCl}$. Для проведения электронно-микроскопических in situ исследований, пленки, напыленные на $\mathrm{NaCl}$, отделяли от подложки в дистиллированной воде, а затем высаживали на электронно-микроскопическую объектную сеточку, изготовленную из молибдена.

Исследование микроструктуры, фазового и элементного состава осуществляли при помощи просвечивающего электронного микроскопа JEOL JEM-2100, оборудованного энергодисперсионным спектрометром Oxford Inca X-sight. Нагрев пленок осуществляли непосредственно в колонне просвечивающего электронного микроскопа при помощи специального держателя образцов, предназначенного для нагрева от комнатной температуры до $+1000^{\circ} \mathrm{C}$. Этот метод был успешно использован для исследования структурных фазовых превращений, протекающих в процессе твердофазных реакций в тонкопленочных наносистемах: $\mathrm{Al} / \mathrm{Au}$ [22], $\mathrm{Cu} / \mathrm{Au}$ [23], $\mathrm{Fe} / \mathrm{Pd}$ [23-25], Fe/Si [26], $\mathrm{Fe}-\mathrm{ZrO}_{2}$ [27], $\mathrm{Co}-\mathrm{ZrO}_{2}$ [28], $\mathrm{Al} / \mathrm{Pt}[29]$.

Фазовый состав исследованных образцов определяли на основе анализа картин дифракции электронов, полученных методом микродифракции от областей диаметром $\approx 1.3 \mu \mathrm{m}$. Анализ электронограмм проведен с использованием программных комплексов CrystBox [30],
Digital Micrograph [31], Process Diffraction [32] и базы данных кристаллических структур ICDD PDF 4+ [33].

\section{3. Экспериментальные результаты и их обсуждение}

Для проведения электронно-микроскопических исследований получена серия двухслойных тонкопленочных наносистем $\mathrm{Al} / \mathrm{Fe}$ (атомное соотношение $\mathrm{Al}: \mathrm{Fe} \approx 1: 1$ ). Суммарная толщина двухслойной наносистемы составила $\approx 50 \mathrm{~nm}$. Толщины индивидуальных нанослоев подбирали таким образом, чтобы обеспечить атомное соотношение $\mathrm{Al}: \mathrm{Fe} \approx 1: 1$. Толщина слоя $\mathrm{Fe}$ составляла $\approx 20 \mathrm{~nm}$, толщина слоя $\mathrm{Al} \approx 30 \mathrm{~nm}$.

Анализ элементного состава, проведенный методом энергодисперсионной спектроскопии, показал, что содержание $\mathrm{Fe}$ в полученных образцах составляет $50 \pm 0.5$ at.\%, содержание $\mathrm{Al}-50 \pm 0.5$ at.\%. Анализ электронно-микроскопических изображений (рис. 1, $a$ ) и картин дифракции электронов (рис. 1,b), полученных от образцов в исходном состоянии, показал, что тонкопленочные наносистемы состоят из кристаллитов $\alpha$-Fe (пространственная группа Im-3m, параметр решетки $a=2.866 \AA$, PDF 4+ card \#00-006-0696) и $\mathrm{Al}$ (пространственная группа Fm-3m, параметр решетки $a=4.049 \AA$, PDF 4+ card \#00-004-0787). Размер кристаллитов $\mathrm{Fe}$ и $\mathrm{Al}$ составил 10-20 nm. На электронограмме (см. рис. 1,b) наблюдается полный набор дифракционных рефлексов поликристаллического типа, соответствующих объемно-центрированной кубической (ОЦК) решетке $\alpha$-Fе и гранецентрированной кубической (ГЦК) решетке Al. 

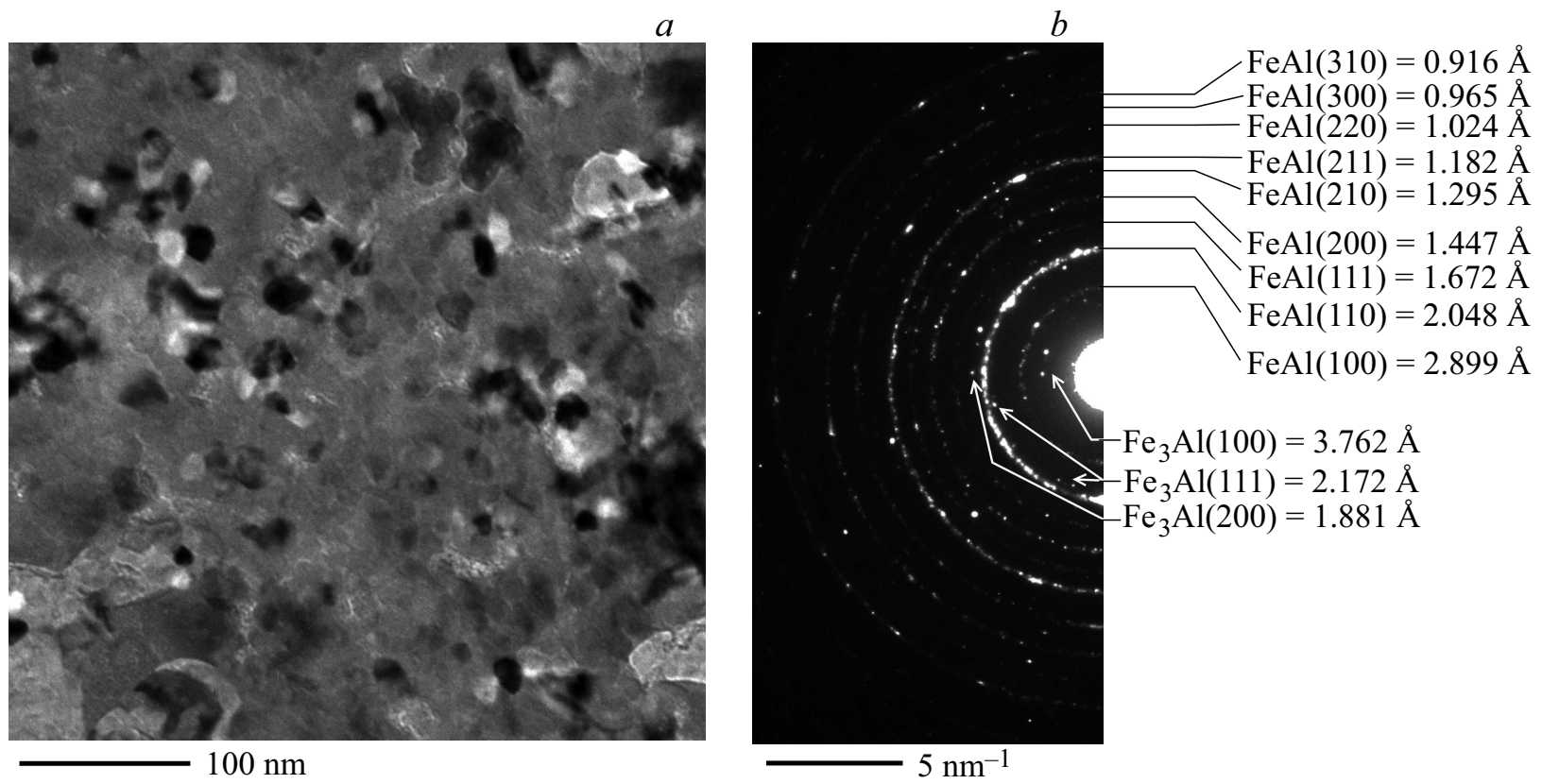

Рис. 2. Электронно-микроскопическое изображение $(a)$ и картина дифракции электронов $(b)$, полученные от тонкопленочной наносистемы $\mathrm{Al} / \mathrm{Fe}$ после нагрева до $850^{\circ} \mathrm{C}$.

С целью изучения процессов фазообразования при твердофазной реакции между нанослоями $\mathrm{Fe}$ и $\mathrm{Al}$, полученные тонкопленочные наносистемы $\mathrm{Al} / \mathrm{Fe}$ были нагреты со скоростью $8^{\circ} \mathrm{C} / \mathrm{min}$ от комнатной температуры до $850^{\circ} \mathrm{C}$. В процессе нагрева образца производили регистрацию картин дифракции электронов со скоростью 4 кадра в минуту, таким образом, один кадр соответствовал изменению температуры образца на $2^{\circ} \mathrm{C}$. Это позволило определить температуру инициирования твердофазной реакции, исследовать динамику и процессы образования твердых растворов, установить последовательность образования фаз в процессе твердофазной реакции.

В температурном диапазоне $250-402^{\circ} \mathrm{C}$ на картинах дифракции электронов наблюдали формирование точечных кристаллических рефлексов слабой интенсивности. Анализ электронограмм позволяет предположить, что наблюдаемые рефлексы принадлежат интерметаллическим соединениям Al-Fe. Однако точная идентификация конкретной интерметаллической фазы (или фаз) Al-Fe не представляется возможной из-за недостаточного количества наблюдаемых рефлексов и их слабой интенсивности.

В температурном диапазоне $404-669^{\circ} \mathrm{C}$ на картинах дифракции электронов наблюдали точечные дифракционные рефлексы, которые могут быть приписаны как фазе $\mathrm{FeAl}_{6}$ (пространственная группа $C$ cm21, параметры решетки: $a=7.440 \AA, b=8.779 \AA, c=6.464 \AA$, PDF 4+ card \#04-007-0980), так и $\mathrm{Fe}_{2} \mathrm{Al}_{5}$ (пространственная группа $C m c m$ (63), параметры решетки: $a=6.413 \AA$, $b=7.649 \AA, c=4.216 \AA$, PDF $4+$ card \#00-047-1435). Однако, из-за близких значений межплоскостных рассто- яний, характерных для фаз $\mathrm{FeAl}_{6}$ и $\mathrm{Fe}_{2} \mathrm{Al}_{5}$ интерпретация этих рефлексов затруднена. Анализ картин дифракции электронов показал, что интерметаллические соединения на данном этапе твердофазной реакции формируются в виде отдельных кристаллитов размером 30-40 nm.

При температуре $480^{\circ} \mathrm{C}$ отмечено начало формирования фазы FeAl (пространственная группа Pm-3m, параметр решетки $a=2.895 \AA$, PDF 4+ card \#00-033-0020), что сопровождалось появлением на электронограммах кольцевых рефлексов, характерных для этой фазы. При достижении температуры $671^{\circ} \mathrm{C}$ на картинах дифракции электронов наблюдали появление точечных дифракционных рефлексов, характерных для фазы $\mathrm{Fe}_{3} \mathrm{Al}$ (пространственная группа $P m-3 m$, параметр решетки $a=3.762 \AA$, PDF 4+ card \# 04-005-9518).

Анализ электронно-микроскопических изображений (рис. 2,a) и картин дифракции электронов (рис. 2,b), полученных от образца после нагрева до $850^{\circ} \mathrm{C}$, показал, что образец состоит из кристаллитов фазы FeAl размером 20-40 nm и немногочисленных отдельных кристаллитов фазы $\mathrm{Fe}_{3} \mathrm{Al}$, размер которых составляет 30-50 nm. Анализ электронограмм при помощи программного комплекса Process Diffraction [32] показал, что фаза $\mathrm{Fe}_{3} \mathrm{Al}$ после нагрева присутствует в пленке в количестве $\approx 2.2 \mathrm{vol} . \%$.

Анализ дифракционных рефлексов на электронограммах, полученных при нагреве до $400^{\circ} \mathrm{C}$, показывает, что в процессе нагрева происходит уменьшение диаметров всех наблюдаемых кольцевых рефлексов. Это свидетельствует об изменении параметров кристаллических решеток алюминия и железа без изменения их типа. Необходимо отметить, что большая часть дифракци- 

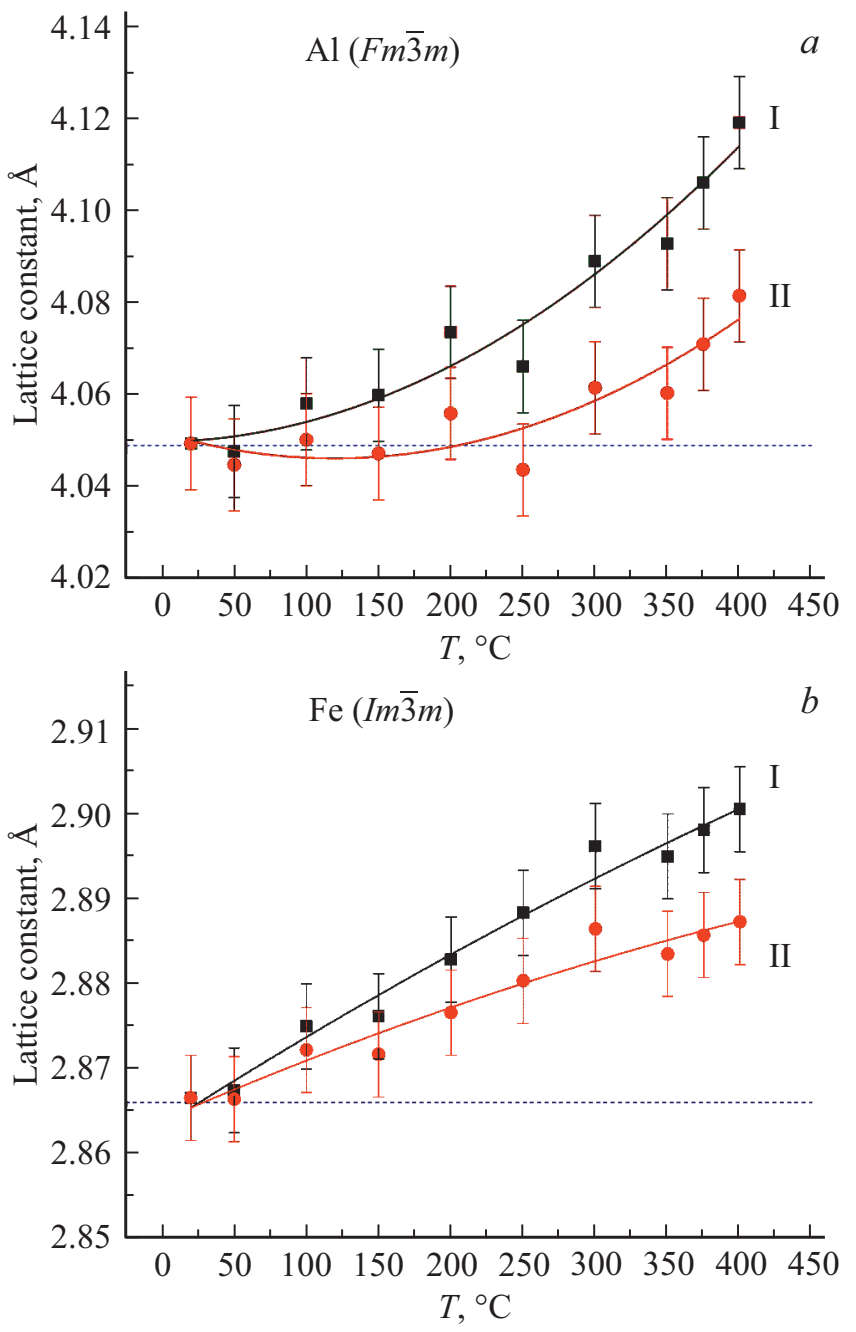

Рис. 3. Изменение параметра решетки алюминия $(a)$ и железа $(b)$ в процессе нагрева тонкопленочной наносистемы $\mathrm{Al} / \mathrm{Fe}$ до $400^{\circ} \mathrm{C}$ (кривые I - без учета ТКЛР, кривые II - c учетом ТКЛР).

онных рефлексов фаз ГЦК алюминия и ОЦК железа практически совпадает (например, $\mathrm{Al} d(200)=2.024 \AA$, Fe $d(110)=2.027 \AA$ ), что создает затруднения в определении параметров решетки ГКЦ алюминия и ОЦК железа. В случае ГЦК алюминия существует характерный, не совпадающий с рефлексами ОЦК железа, рефлекс (111), на основе которого было рассчитано изменение параметра решетки ГЦК алюминия в ходе нагрева. Параметр решетки ОЦК железа рассчитывали на основании анализа положения рефлекса (110) $\alpha$-Fe, который совпадает с рефлексом (200) Al, но при этом обладает намного большей абсолютной интенсивностью.

На рис. 3, $a, b$ представлены зависимости изменения параметров решеток $\mathrm{Al}$ и $\alpha$-Fe в процессе нагрева пленок до $400^{\circ} \mathrm{C}$. Кривые I и II на рис. $3, a, b$ представляют изменение параметров решеток $\mathrm{Al}$ и $\alpha$-Fe соответственно без учета и с учетом температурного коэффициента линейного расширения (ТКЛР).
Анализ изменения параметра решетки $\alpha$-Fe в процессе нагрева (см. рис. 3, $b$ кривая II) показывает, что увеличение параметра решетки железа начинается при $\approx 100^{\circ} \mathrm{C}$, при этом параметр решетки алюминия остается неизменным, в пределах ошибки измерений, вплоть до $\approx 250^{\circ} \mathrm{C}$ (см. рис. 3, $a$ кривая II). Это свидетельствует о формировании в пленке неупорядоченного твердого раствора $\mathrm{Al}$ в $\alpha$-Fe с ОЦК решеткой уже при $100^{\circ} \mathrm{C}$. Согласно данным работы [34], наблюдаемое в настоящей работе изменение параметра решетки $\alpha$-Fe (см. рис. $3, b$ кривая II) с $2.866 \AA$ (исходное состояние) до $2.886 \AA$ $\left(300^{\circ} \mathrm{C}\right)$ соответствует твердому раствору $\mathrm{Fe}(\mathrm{Al})$, содержащему $\approx 8$ at.\% алюминия.

Анализ изменения параметра решетки алюминия (см. рис. 3, $a$ кривая II) при $T>250^{\circ} \mathrm{C}$ позволяет предположить, что наблюдаемое увеличение параметра решетки не является реальным и связано с формированием интерметаллических фаз, а не твердого раствора $\mathrm{Al}(\mathrm{Fe})$. Согласно данным работы [34] формирование твердого раствора $\mathrm{Al}(\mathrm{Fe})$ должно сопровождаться уменьшением, а не увеличением параметра решетки алюминия. В настоящей работе на начальном этапе $\left(250-402^{\circ} \mathrm{C}\right)$ твердофазной реакции интерметаллические соединения $\mathrm{Al}-\mathrm{Fe}$ формируются в виде отдельных кристаллитов, что сопровождается появлением на электронограммах точечных рефлексов с $d=2.35-2.37 \AA$. Так как параметр решетки алюминия в настоящей работе рассчитывается по рефлексу $\mathrm{Al} d(111)=2.34 \AA$, то появление рефлексов интерметаллических фаз приводит к кажущемуся увеличению параметра решетки алюминия. В работах [16-18], посвященных исследованиям двухслойных пленок $\mathrm{Al} / \mathrm{Fe}$, начало твердофазной реакции сопровождалось формированием интерметаллических соединений $\mathrm{FeAl}_{6}$ и/или $\mathrm{Fe}_{2} \mathrm{Al}_{5}$ при $250-330^{\circ} \mathrm{C}$. Можно предположить, что в настоящей работе в температурном диапазоне $250-402^{\circ} \mathrm{C}$ происходит формирование фаз $\mathrm{FeAl}_{6}$ и/или $\mathrm{Fe}_{2} \mathrm{Al}_{5}$ в небольшом объеме на границе раздела нанослоев алюминий-железо.

В результате проведенных исследований фазообразования в процессе твердофазной реакции в тонкопленочных наносистемах Al/Fe (атомное соотношение $\mathrm{Al}: \mathrm{Fe} \approx 1: 1)$ предложена следующая последователь-

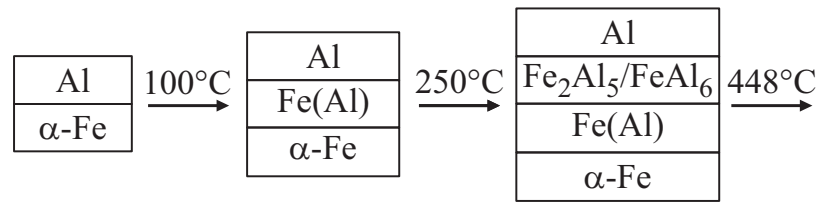

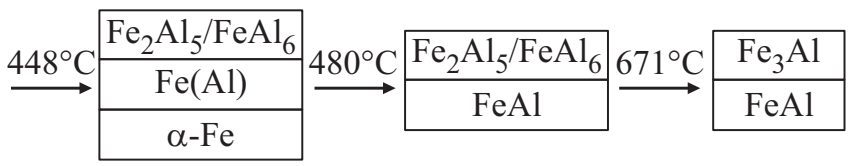

Рис. 4. Схематическое изображение, демонстрирующее последовательность формирования фаз при твердофазной реакции в тонкопленочной наносистеме $\mathrm{Al} / \mathrm{Fe}$. 
Таблица 1. Структурные фазовые превращения в тонкопленочной наносистеме $\mathrm{Al} / \mathrm{Fe}$ при твердофазной реакции, инициированной термическим нагревом со скоростью $8^{\circ} \mathrm{C} / \mathrm{min}$

\begin{tabular}{c|c|c|c|c|c|c}
\hline$T,{ }^{\circ} \mathrm{C}$ & $\mathrm{Al}$ & $\alpha$-Fe & $\begin{array}{c}\mathrm{Fe}(\mathrm{Al}) \\
\mathrm{TB} . \mathrm{p}-\mathrm{p} .\end{array}$ & $\begin{array}{c}\mathrm{FeAl}_{6} \\
\mathrm{Fe}_{2} \mathrm{Al}_{5}\end{array}$ & $\mathrm{FeAl}$ & $\mathrm{Fe}_{3} \mathrm{Al}$ \\
\hline $25-98$ & + & + & & & & \\
$100-248$ & + & + & + & & & \\
$250-402$ & + & + & + & $?$ & & \\
$404-446$ & + & + & + & + & & \\
$448-478$ & & + & + & + & & \\
$480-669$ & & $?$ & $?$ & + & + & \\
$671-850$ & & $?$ & $?$ & & + & $\mathrm{s}$
\end{tabular}

Пр и м е ч ан и е: символ „,“ означает, что фаза присутствует в пленке лишь в небольшом количестве $(<10 \mathrm{wt} . \%)$. Символ „?“ означает, что присутствие данной фазы не исключено.

Таблица 2. Значения теплоты формирования $\Delta H^{0}$ и эффективной теплоты формирования $\Delta H^{\prime}$ фаз $\mathrm{Al}-\mathrm{Fe}$

\begin{tabular}{l|c|c|c}
\hline \multicolumn{1}{|c|}{ Фаза } & $\begin{array}{c}\text { Теплота } \\
\text { (ормирования } \Delta H^{0}, \\
\mathrm{~kJ}^{*}(\text { mol. at. })^{-1}\end{array}$ & $\begin{array}{c}\text { Эффективная } \\
\text { теплота } \\
\text { формирования } \Delta H^{\prime}, \\
\mathrm{kJ}^{*} \text { (mol. at.) }\end{array}$ & Источник \\
\hline $\mathrm{FeAl}_{6}$ & -11 & -0.69 & {$[14]$} \\
$\mathrm{Fe}_{2} \mathrm{Al}_{5}$ & -22 & -0.69 & {$[14]$} \\
$\mathrm{Fe}_{4} \mathrm{Al}_{13}$ & -18 & -0.69 & {$[35]$} \\
$\mathrm{FeAl}_{2}$ & -25 & -0.68 & {$[14]$} \\
$\mathrm{FeAl}_{3}$ & -19 & -0.68 & {$[14]$} \\
$\mathrm{FeAl}_{\mathrm{Fe}} \mathrm{Fl}$ & -32 & -0.58 & {$[35]$} \\
& -22 & -0.26 & {$[14]$}
\end{tabular}

ность формирования фаз:

$\mathrm{Fe}+\mathrm{Al} \rightarrow \mathrm{Fe}(\mathrm{Al}) \rightarrow \mathrm{FeAl}_{6}$ и/или $\mathrm{Fe}_{2} \mathrm{Al}_{5} \rightarrow \mathrm{FeAl} \rightarrow \mathrm{Fe}_{3} \mathrm{Al}$,

представленная также в виде схематического изображения (см. рис. 4).

Температурные области существования интерметаллических соединений формирующихся в процессе твердофазной реакции в тонкопленочной наносистеме $\mathrm{Al} / \mathrm{Fe}$ представлены в табл. 1.

Согласно модели EHF [14] в процессе твердофазной реакции первой формируется фаза, обладающая наименьшей эффективной теплотой формирования $\Delta H^{\prime}$. В табл. 2 представлены теплоты формирования $\Delta H^{0}$ и эффективные теплоты формирования $\Delta H^{\prime}$ для фаз $\mathrm{Fe}-\mathrm{Al}$. Значения $\Delta H^{0}, \Delta H^{\prime}$ фаз $\mathrm{Fe}_{3} \mathrm{Al}, \mathrm{FeAl}_{2}, \mathrm{Fe}_{2} \mathrm{Al}_{5}, \mathrm{FeAl}_{3}, \mathrm{FeAl}_{6}$ взяты из работы [14]. Теплота формирования $\Delta H^{0}$ фаз $\mathrm{FeAl}$ и $\mathrm{Fe}_{4} \mathrm{Al}_{13}$ рассчитана с использованием работы [35]. На основании полученного значения $\Delta H^{0}$ рассчитано значение эффективной теплоты формирования $\Delta H^{\prime}$.

В соответствии с табл. 2 наименьшими значениями эффективной теплоты формирования обладают фазы $\mathrm{Fe}_{2} \mathrm{Al}_{5}, \mathrm{FeAl}_{6}, \mathrm{Fe}_{4} \mathrm{Al}_{13}, \mathrm{FeAl}_{2}$ и $\mathrm{FeAl}_{3}$. Однако значения эффективной теплоты формирования данных фаз отличаются незначительно - всего на $0.01 \mathrm{~kJ}^{*}(\text { mol.at. })^{-1}$. Это означает, что данные фазы должны формироваться в процессе твердофазной реакции практически одновременно. Однако, это не согласуется с экспериментальными результатами как настоящей работы, так и результатами работ других исследователей [16-18]. При этом наблюдаемое в настоящей работе последовательное формирование фаз $\mathrm{FeAl}\left(-0.58 \mathrm{~kJ}^{*}(\text { mol. at. })^{-1}\right) \rightarrow \mathrm{Fe}_{3} \mathrm{Al}$ $\left(-0.26 \mathrm{~kJ}^{*}(\text { mol. at. })^{-1}\right)$ согласуется с моделью ЕНF. Стоит отметить, что формирование фазы $\mathrm{Fe}_{3} \mathrm{Al}$ в тонкопленочных системах ранее только предполагали исходя из анализа магнитных свойств [36] и ее присутствие не было подтверждено прямыми структурными методами. В настоящей работе методом in situ дифракции электронов показано, что фаза $\mathrm{Fe}_{3} \mathrm{Al}$ формируется при температуре $671^{\circ} \mathrm{C}$ в процессе твердофазной реакции между нанослоями $\mathrm{Fe}$ и $\mathrm{Al}$.

\section{4. Заключение}

Исследованы процессы формирования фаз при твердофазной реакции между нанослоями $\mathrm{Fe}$ и $\mathrm{Al}$ (атомное соотношение $\mathrm{Al}: \mathrm{Fe} \approx 1: 1$, толщина индивидуального слоя 20-30 nm). Твердофазная реакция инициирована термическим нагревом в колонне просвечивающего электронного микроскопа. Температура начала реакции и последовательность образования фаз определены на основании данных, полученных методом in situ дифракции электронов непосредственно в процессе твердофазной реакции. Установлено, что процесс твердофазной реакции на границе нанослоев алюминия и железа начинается при $\approx 100^{\circ} \mathrm{C}$ с формирования неупорядоченного твердого раствора $\mathrm{Al}$ в $\alpha$-Fe. Показано, что в ходе дальнейшего нагрева последовательно формируются интерметаллические фазы $\mathrm{FeAl}_{6}$ и/или $\mathrm{Fe}_{2} \mathrm{Al}_{5}, \mathrm{FeAl}, \mathrm{Fe}_{3} \mathrm{Al}$. Впервые прямым структурным методом зарегистрировано формирование фазы $\mathrm{Fe}_{3} \mathrm{Al}$ при твердофазной реакции в тонкопленочной наносистеме $\mathrm{Al} / \mathrm{Fe}$.

\section{Финансирование работы}

Работа выполнена при финансовой поддержке Российского фонда фундаментальных исследований (грант № 18-03-01173a).

\section{Конфликт интересов}

Авторы заявляют, что у них нет конфликта интересов.

\section{Список литературы}

[1] H.Y. Gao, Y.H. He, P.Z. Shen, Y. Jiang, C.T. Liu. Adv. Powder Technol. 26, 882 (2015).

[2] Y. Liu, X. Chong, Y. Jiang, R. Zhou, J. Feng. Phys. B Condens. Matter 506, 1 (2017).

[3] M. Palm. Int. J. Mater. Res. 100, 277 (2009). 
[4] P. Mengucci, G. Majni, A. Di Cristoforo, R. Checchetto, A. Miotello, C. Tosello, G. Principi. Thin Solid Films 433, 205 (2003).

[5] T. Abe, T. Kawai, M. Futamoto, M. Ohtake, N. Inaba. AIP Adv. 8, (2018).

[6] Y. Wei, W. Shao, Z. Ma, Z. Chen, W. Lu. Mater. Lett. 185, 537 (2016).

[7] А.С. Рогачев. Успехи химии 77, 22 (2008).

[8] В.Г. Мягков, В.С. Жигалов, Л.Е. Быкова, В.К. Мальцев. ЖТФ 10, 58 (1998).

[9] A.S. Rogachev, S.G. Vadchenko, A.A. Nepapushev, A.S. Mukasyan. Int. J. Self-Propagating High-Temperature Synth. 25, 234 (2016).

[10] D.J. Fisher. Bonding by Self-Propagating Reaction (Materials Research Forum LLC, 2019), ISBN-10: 1644900084.

[11] R. Checchetto, C. Tosello, A. Miotello, G. Principi. J. Phys. Condens. Matter 13, 811 (2001).

[12] S. Jani, V. Sebastian, N. Lakshmi, V.R. Reddy, K. Venugopalan, A. Gupta, N.P. Lalla. J. Appl. Phys. 104, 123907 (2008).

[13] J.M. Poate, K.N. Tu, J.W. Mayer. Thin Films — Interdiffusion and Reactions (1982).

[14] R. Pretorius, T. Marais, C. Theron. Mater. Sci. Rep. 10, 1 (1993).

[15] K. Bhanumurthy, W. Krauss, J. Konys. Fusion Sci. Technol. 65, 262 (2014).

[16] F. Haidara, M.-C. Record, B. Duployer, D. Mangelinck. Intermetallics 23, 143 (2012).

[17] A. Csanády, J.R. Günter, P.B. Barna, J. Mayer. Thin Solid Films 167, 203 (1988).

[18] S.R. Teixeira, F.L. Freire, I.J.R. Baumvol. Appl. Phys. A 48, 481 (1989).

[19] P. Bhattacharya, K.N. Ishihara, K. Chattopadhyay. Mater. Sci. Eng. A 304-306, 250 (2001).

[20] J.L. Alexandre, M.A.Z. Vasconcellos, S.R. Teixeira, I.J.R. Baumvol. Appl. Phys. A 56, 113 (1993).

[21] ADVENT Research Materials Ltd, Oxford, UK., www.advent-rm.com.

[22] Р.Р. Алтунин, С.М. Жарков. Изв. РАН. Сер. физ. 77, 1107 (2013).

[23] S.M. Zharkov, E.T. Moiseenko, R.R. Altunin. J. Solid State Chem. 269, 36 (2019).

[24] С.М. Жарков, Е.Т. Моисеенко, Р.Р. Алтунин, Н.С. Николаева, В.С. Жигалов, В.Г. Мягков. Письма в ЖЭТФ 99, 472 (2014).

[25] Е.Т. Моисеенко, Р.Р. Алтунин, С.М. Жарков. ФТТ 59, 1208 (2017).

[26] S.M. Zharkov, R.R. Altunin, E.T. Moiseenko, G.M. Zeer, S.N. Varnakov, S.G. Ovchinnikov. Solid State Phenom. 215, 144 (2014).

[27] V.G. Myagkov, L.E. Bykova, O.A. Bayukov, V.S. Zhigalov, I.A. Tambasov, S.M. Zharkov, A.A. Matsynin, G.N. Bondarenko. J. Alloys Compd. 636, 223 (2015).

[28] V.G. Myagkov, V.S. Zhigalov, L.E. Bykova, S.M. Zharkov, A.A. Matsynin, M.N. Volochaev, I.A. Tambasov, G.N. Bondarenko. J. Alloys Compd. 665, 197 (2016).

[29] Р.Р. Алтунин, Е.Т. Моисеенко, С.М. Жарков. ФТТ 60, 1397 (2018).

[30] M. Klinger, A. Jäger. J. Appl. Crystallogr. 48, 2012 (2015).
[31] Gatan Inc. Digital Micrograph. Pleasanton, California. (2007).

[32] J.L.Lábár. Proc. Eurem 12, 379 (2000).

[33] Powder Diffraction File (PDF 4+, 2018), Inorganic Phases, International Center for Diffraction Data, Swarthmore, PA, USA.

[34] Landolt-Börnstein. New Ser. Group IV. V. 5A / Ed. B. Predel, O. Madelung, Springer-Verlag 1991, ISBN 978-3-540-15516-4.

[35] A. Debski, R. Debski, W. Gasior. Arch. Metall. Mater. 59, 1337 (2014).

[36] R. Brajpuriya. Surf. Interface Anal. 50, 1349 (2018).

Редактор Т.Н. Василевская 